\title{
Overexpression of asparaginyl endopeptidase is significant for esophageal carcinoma metastasis and predicts poor patient prognosis
}

\author{
XINYANG LIU ${ }^{1 *}$, ZHICHAO WANG ${ }^{2 *}$, GUOLIANG ZHANG ${ }^{3 *}$, QIKUN ZHU $^{3}$, HUI ZENG ${ }^{3}$, \\ TAO WANG ${ }^{3}$, FENG GAO $^{3}$, ZHAN QI $^{3}$, JINWEN ZHANG ${ }^{4}$ and RUI WANG ${ }^{3}$
}

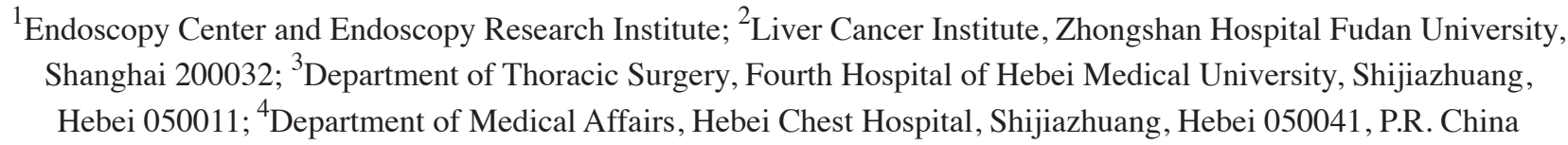

Received September 23, 2016; Accepted September 22, 2017

DOI: $10.3892 / \mathrm{ol} .2017 .7433$

\begin{abstract}
Esophageal cancer is one of the most common types of cancer with poor prognosis. The molecular mechanisms of esophageal cancer progression remain unknown. In the present study, the aim was to investigate the clinical significance and biological function of protease asparaginyl endopeptidase (AEP) in esophageal cancer. The expression of AEP in esophageal cancer was examined, and its association with clinicopathological factors and patient prognosis was analyzed. A series of functional and mechanistic assays were performed to further investigate the underlying molecular mechanisms, and functions in esophageal cancer. The expression of AEP was elevated in esophageal cancer tissues, and patients with high AEP expression displayed a significantly shorter survival time compared with those with low AEP expression. In addition, loss of function experiments demonstrated that knockdown of AEP significantly reduced the migration and invasion ability of esophageal cancer cells. Furthermore, the pro-oncogenic effects of AEP in esophageal cancer were mediated by the upregulation of matrix-metalloproteinase 2 and 3. Taken together, the data from the present study indicates that high AEP expression is associated with esophageal cancer progression and AEP is an indicator of poor prognosis in patients with esophageal cancer. AEP therefore, may be considered as a
\end{abstract}

Correspondence to: Professor Rui Wang, Department of Thoracic Surgery, Fourth Hospital of Hebei Medical University, 12 Jiankang Road, Shijiazhuang, Hebei 050011, P.R. China

E-mail:hbssywr@sohu.com

Dr Jinwen Zhang, Department of Medical Affairs, Hebei Chest Hospital, 372 Sheng Li Street, Shijiazhuang, Hebei 050041, P.R. China

E-mail:hbxkjw@163.com

*Contributed equally

Key words: asparaginyl endopeptidase, esophageal cancer, prognosis, invasion, matrix-metalloproteinase novel prognostic biomarker or potential therapeutic target in esophageal cancer.

\section{Introduction}

Esophageal cancer (EC) is the eighth most common type of cancer and the sixth most common cause of cancer-associated mortality worldwide $(1,2)$. In 2003 a study published in New England Journal of Medicine indicated that the worldwide overall 5-year survival rate of EC was $<15 \%$ (3). Poor outcomes in patients with esophageal cancer are associated with diagnosis at advanced (metastatic) stages and the propensity for metastases $(4,5)$. Therefore, there is a requirement to investigate the underlying mechanisms of EC progression, particularly metastasis, to identify potential biomarkers for prognosis and diagnosis.

AEP, currently the only known asparaginyl endopeptidase in the mammalian genome, is a member of the C13 family in the MEROPS database classification of peptidases, whereas all other lysosomal cysteine proteases identified to date are grouped in the $\mathrm{C} 1$ family $(6,7)$. The strict specificity of AEP to asparagine bonds is notable (8). AEP has been demonstrated to contribute important functions in kidney physiology, immunity, atherogenesis and bone metabolism (9-15). In previous years, high AEP expression has been observed in a variety of solid tumors and acute lymphoblastic leukemia (16-21). Furthermore, AEP expression positively correlated with clinicopathological and biological variables in colorectal, and breast cancer $(19,20)$. Although cancer cells that highly express AEP have been revealed to exhibit enhanced migratory and invasive capacity through the activation of pro-matrix-metalloproteinase 2 (MMP2), and cathepsins (17,22,23), the pathological functions and underlying mechanisms of AEP in esophageal cancer remain elusive.

In the present study, it was demonstrated that AEP expression was elevated in a cohort of esophageal cancer tissues. Patients with EC with high AEP expression exhibited a significantly poorer overall survival rate. Additionally, loss of function experiments revealed that knockdown of AEP significantly reduced the migration and invasion ability of EC cells 
through downregulation of MMP2 and MMP3. The results of the present study indicate that high AEP expression promotes progression and indicates poor prognosis in patients with esophageal cancer, indicating it a novel prognostic biomarker or potential therapeutic target in esophageal cancer.

\section{Materials and methods}

Patients and tissue samples. The present study was approved by the Ethics Committee of the Fourth Hospital of Hebei Medical University (Hebei, China). Written informed consent was obtained from patients or guardians on behalf of the minors enrolled in the study. A total of 146 patients with histologically confirmed esophageal cancer at the Fourth Hospital of Hebei Medical University were recruited for this study between January 2005 and December 2013. There were 111 male patients and 35 female patients with a median age of 57 years (range, 34-72 years). The specimens were obtained during surgical resection and matched adjacent normal tissues were also collected. Their diagnoses were independently re-reviewed by two pathologists, classified by the World Health Organization criteria (24).

Cell lines. Esophageal cancer EC109 and TE-1 cell lines were obtained from the Type Culture Collection of the Chinese Academy of Sciences (Shanghai, China) and the two cell lines were cultured in RPMI-1640 (Gibco; Thermo Fisher Scientific, Inc., Waltham, MA, USA) supplemented with $10 \%$ fetal bovine serum (FBS; Gibco; Thermo Fisher Scientific, Inc.) at $37^{\circ} \mathrm{C}$ and $5 \% \mathrm{CO}_{2}$. EC109 and TE-1 cells were used to determine baseline AEP expression and EC109 cells were selected to conduct following experiments.

Immunohistochemistry (IHC). A total of 146 blocks of tissue microarray containing EC tissues were constructed using a Microarrayer. Serial $4-\mu \mathrm{m}$ sections were obtained from each block, with the first slide being stained for hematoxylin and eosin to confirm pathologic diagnosis, and the subsequent slides stained for further IHC.

Tissue microarray slides were routinely deparaffinizated and rehydrated. For antigen retrieval, the slides were heated at $98^{\circ} \mathrm{C}$ in a citrate buffer $(\mathrm{pH} 9.0)$ for a total of $20 \mathrm{~min}$ and cooled naturally to room temperature. Sections were incubated in $0.3 \%$ hydrogen peroxide for $20 \mathrm{~min}$ to inactivate endogenous peroxidases at room temperature. The sections were blocked with 5\% normal horse serum (Sigma-Aldrich; Merck KGaA, Darmstadt, Germany) in PBS for 30 min and then incubated with the monoclonal primary antibody against AEP (1:100 dilution; cat. no. AF2199; R\&D Systems, Inc., Minneapolis, MN, USA), overnight at $4^{\circ} \mathrm{C}$. The following day, sections were stained using a highly sensitive streptavidin-biotin-peroxidase detection system (MaxVision TM HRP-Polymer anti-Mouse IHC kit; cat. no. KIT-5001; Maixin Biotechnology, Fuzhou, China) and counterstained with hematoxylin. A negative control was also incorporated using pre-immune IgG instead of the primary antibody. All slides were observed and image captured using a light microscope.

Evaluation of immunohistochemistry. Two sections per specimen were evaluated by two pathologists independently.
Immunoreactive staining was characterized quantitatively according to the percentage of positive cells and staining intensity without prior knowledge of any of the clinicopathological information. The following proportion scores were assigned as: $0,0 \%$ of the tumor cells showed positive staining; $1,0-10 \%$ stained; $2,11-50 \%$ stained; $3,51-75 \%$ stained and $4,75-100 \%$ stained. The intensity of staining was rated on a scale of 0 to 3 : 0 , negative; 1 , weak; 2 , moderate and 3 , strong. The proportion and intensity scores were combined to obtain a total score (range 0-12). All patients were designated into negative (score 0), low (score 1-4), moderate (score 5-8) and high (score 9-12) groups based on AEP expression.

Western blot analysis. To analyze AEP expression in EC109 and TE-1 cell lines, western blot assays were performed. Briefly, cells were lysed using radioimmunoprecipitation assay buffer [50 mM Tris- $\mathrm{HCl}$ (pH 7.5), $150 \mathrm{mM} \mathrm{NaCl,} 1 \%$ Triton $\mathrm{X}-100,0.5 \%$ Na-deoxycholate] containing protease inhibitors (CompleteMini; Roche Applied Science, Penzberg, Germany). The concentration of protein was determined using a BCA kit (Beyotime Institute of Biotechnology, Shanghai, China). Total protein (20-30 $\mu \mathrm{g}$ per lane) of the lysates were separated on $8-12 \%$ SDS-PAGE gels and transferred to polyvinylidene fluoride membranes. The membranes were firstly blocked with 5-10 $\mathrm{ml}$ western blocking reagent (Quickblock ${ }^{\mathrm{TM}}$; cat. no. P0220; Beyotime Institute of Biotechnology) at room temperature for $2 \mathrm{~h}$ and then incubated with primary antibodies, goat anti-human AEP (cat. no. AF2199; R\&D Systems; 1:1,000) and rabbit anti-actin (cat. no. EP1123Y; EMD Millipore, Billerica, CA, USA; 1:10,000), overnight at $4^{\circ} \mathrm{C}$. Subsequently, membranes were incubated with a horseradish peroxidase-conjugated secondary antibody (donkey anti-goat; cat. no. A0181; 1:10,000; or goat anti-rabbit; cat. no. A0208; 1:10,000; Beyotime Institute of Biotechnology). The membranes were incubated with secondary antibodies at room temperature for $2 \mathrm{~h}$. The bound antibodies were detected using an enhanced chemiluminescence kit (Pierce; Thermo Fisher Scientific, Inc.; cat. no. PI32209).

Lentiviral vector mediated AEP-knockdown. Lentiviral vectors for human AEP-specific short hairpin RNA (shRNA) carrying a green fluorescent protein (GFP) sequence were constructed by Hanyin Co. (Shanghai, China). The recombinant AEP knockdown lentivirus and the negative control (NC) lentivirus (GFP-lentivirus; Hanyin Co., Shanghai, China) were prepared, and titered to $109 \mathrm{TU} / \mathrm{ml}$ (transfection unit). The AEP shRNA sequences were AEP-KD1, 5'-GCTCTTGGT GGATCATCAA-3'; and AEP-KD2, 5'-GCATGTTCAATG GGAGCTTGGA-3'. After 48 h, the knockdown efficiency was confirmed via reverse transcription-quantitative polymerase chain reaction (RT-qPCR) and western blotting. To obtain the stable AEP-knockdown cell line, EC109 cells were seeded at a density of $2 \times 10^{5}$ cells/well in 6-well dishes. The cells were then infected with the same titer virus with $8 \mu \mathrm{g} / \mathrm{ml}$ polybrene on the following day. At $\sim 72 \mathrm{~h}$ post-viral infection, GFP expression was confirmed under a fluorescence microscope, and the culture medium was replaced with RPMI-1640 containing $4 \mu \mathrm{g} / \mathrm{ml}$ puromycin (Thermo Fisher Scientific, Inc.). The cells were then cultured for at least 14 days at $37^{\circ} \mathrm{C}$. The puromycin-resistant cell clones were isolated, amplified in 

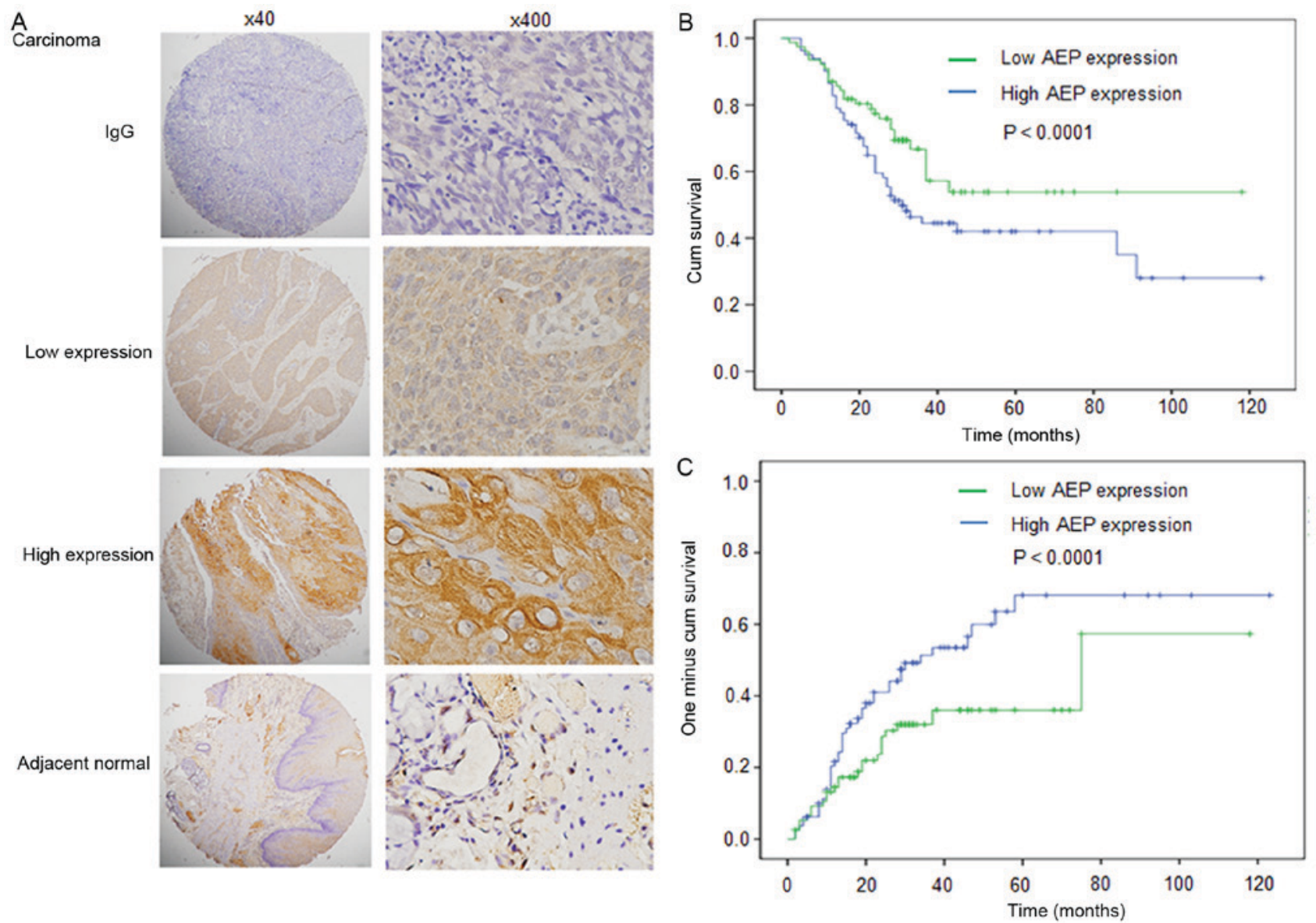

Figure 1. High AEP expression in esophageal carcinoma was associated with poor prognosis and high recurrence. (A) Immunohistochemical staining of AEP was performed on EC and normal adjacent tissue specimens. Images of representative low and high AEP staining are presented. IgG was used as negative control. Images were captured at magnification, $x 40$ and x400. (B) Kaplan-Meier curves of AEP expression in tumour tissues in relation to overall survival $(\mathrm{P}<0.001)$. (C) Kaplan-Meier curves of AEP expression in tumour tissues in relation to one minus overall survival ( $<<0.001)$. AEP, asparaginyl endopeptidase; EC, esophageal carcinoma; IgG, immunoglobulin.

medium containing $2 \mu \mathrm{g} / \mathrm{ml}$ puromycin for 7-9 days and transferred to a medium without puromycin.

Matrigel-Transwell assay. EC109 and AEP-knockdown EC109 cells (1,000 per well) were then plated in the top chamber of Transwell assay inserts (EMD Millipore) with a Matrigel-coated membrane containing $8-\mu \mathrm{m}$ pores in $200 \mathrm{ml}$ of serum-free RPMI-1640 medium. The assays were conducted in triplicate. The inserts were then placed into the bottom chamber of a 24-well plate containing RPMI 1640 supplemented with $10 \%$ FBS as a chemoattractant. After $24 \mathrm{~h}$, the top layer of the insert was scraped with a sterile cotton swab to remove any remaining cells. The invading cells on the bottom surface were stained with $0.1 \%$ crystal violet at room temperature for $2 \mathrm{~h}$, examined, counted, and imaged using a light microscope. The number of cells in five random fields of each chamber was counted, and an average number of cells were calculated.

Scratch assay. EC109 and AEP-knockdown EC109 cells were then plated into 6-well plates in $200 \mathrm{ml}$ of serum-free RPMI 1640 medium at a density of 10,000 per well. The assays were conducted in triplicate. The inserts were then placed into the bottom chamber of a 24-well plate containing RPMI 1640 with $10 \%$ FBS as a chemoattractant. After $24 \mathrm{~h}$, the top layer of the insert was scraped with a sterile cotton swab to remove any remaining cells. The invading cells on the bottom surface were stained $0.1 \%$ crystal violet at room temperature for $2 \mathrm{~h}$, examined, counted, and images were captured using a light microscope. The number of cells in five random fields of each chamber was counted, and an average number of cells were calculated.

Statistical analysis. Survival was calculated starting from the date of surgery to date of death or last follow-up. Survival curves for AEP were plotted using the Kaplan-Meier and compared using the log-rank test. Cox proportional hazard models were used for univariate and multivariate analysis to test clinical features for their associations with overall survival. In the multivariate Cox model, variables with $\mathrm{P}<0.1$ from the univariate model were included. In addition to AEP expression, the following variables were considered: Age, sex, grading and tumor location. Median times and hazard ratios are presented with $95 \%$ confidence intervals (CIs). All statistical analyses were performed using SPSS for Windows v.17.0 (SPSS, Chicago, IL, USA). Two-tailed $\mathrm{P}<0.05$ was considered to indicate a statistically significant difference. 


\section{Results}

High AEP expression in esophageal carcinoma is associated with poor prognosis. Immunostaining was conducted to analyze the expression and intracellular location of AEP in 146 patient samples with esophageal carcinoma. Representative expression patterns in esophageal carcinoma samples are presented in Fig. 1A. Positive staining of AEP revealed predominantly cytoplasmic localization in cancerous tissues and AEP expression was higher in cancerous tissues compared with adjacent normal tissues (Fig. 1A).

According to AEP expression in esophageal carcinoma samples, all cases were distributed into two sub-groups: Low AEP expression group $(n=70)$ and high AEP expression group $(n=76)$ (Fig. 1A; Table I). Following the evaluation of immunohistochemical staining, AEP levels in high-grade cases were significantly increased compared with that in low-grade cases (Table I; P=0.066).

To evaluate the association of AEP expression with patient prognosis, a log-rank test and Kaplan-Meier analysis were introduced to assess the effect of AEP expression on patient survival and relapse. The log-rank test (univariate analysis) revealed that patients with low level of AEP expression in tumor tissues demonstrated significantly longer overall survival compared with patients with high AEP expression ( $n=146$; Fig. 1B-C; Table II; P=0.019). Factors including the drinking history, $\mathrm{N}$ stage and TNM stage also affected OS. However, AEP expression did not affect time to relapse.

Further, multivariate COX regression analysis was also performed to explore whether AEP was an independent prognostic factor for patient survival. As shown in Table II, AEP expression was not an independent prognosis factor (HR, 1.669; 95\% CI, 0.982-2.838; $\mathrm{P}=0.058)$.

AEP expression in esophageal cancer cell lines. AEP is reported to be overexpressed in multiple types of human solid tumors and acute lymphoblastic leukemia compared with normal tissues (16-21). In the present study, it was demonstrated that AEP mRNA and protein levels were increased in EC109 and TE-1 esophageal cancer cell lines. The messenger RNA level of AEP was analyzed by reverse transcription-quantitative polymerase chain reaction using the PrimeScript RT reagent kit and TaKaRa Premix Ex Taq kit. The protein expression level of AEP was analyzed by western blot analysis. AEP has two molecular mass isoforms, the inactive zymogen (pro-AEP) of $\sim 56 \mathrm{kDa}$ and the mature enzyme (active AEP) of $\sim 36 \mathrm{kDa}$ (Fig. 2) (5). qPCR and western blot analysis demonstrated that AEP expression levels were highest in the hEEC cell line, followed by the EC109, and TE-1 cells (Fig. 2A and B).

Effects of AEP on the migration and invasion of esophageal cancer cells. To investigate the effects of AEP on esophageal cancer metastasis, the migration and invasion ability of esophageal cancer cells were analyzed. Control and AEP-silenced EC109 cells were subjected to a migration assay. A target-shRNA to knockdown endogenous AEP in esophageal cancer cell line EC109 was employed. Two different shRNAs were designed to exclude off-target effects. Efficient AEP knockdown was demonstrated by
Table I. Associations between tumor AEP expression and clinicopathologic features.

\begin{tabular}{|c|c|c|c|}
\hline \multirow[b]{2}{*}{ Characteristics } & \multicolumn{3}{|c|}{ AEP } \\
\hline & Low & High & P-value \\
\hline \multicolumn{4}{|l|}{ Age, years } \\
\hline$\leq 60$ & 38 & 46 & 0.146 \\
\hline$>60$ & 32 & 30 & \\
\hline \multicolumn{4}{|l|}{ Sex } \\
\hline Female & 20 & 15 & 0.276 \\
\hline Male & 50 & 61 & \\
\hline \multicolumn{4}{|l|}{ Drinking history } \\
\hline No & 25 & 23 & 0.137 \\
\hline Yes & 45 & 53 & \\
\hline \multicolumn{4}{|l|}{ Smoking history } \\
\hline No & 25 & 23 & 0.300 \\
\hline Yes & 45 & 53 & \\
\hline \multicolumn{4}{|c|}{ Family cancer history } \\
\hline No & 49 & 58 & 0.208 \\
\hline Yes & 21 & 18 & \\
\hline \multicolumn{4}{|l|}{ T Stage } \\
\hline I and II & 29 & 24 & 0.144 \\
\hline III and IV & 41 & 52 & \\
\hline \multicolumn{4}{|l|}{ N Stage } \\
\hline No & 44 & 43 & 0.273 \\
\hline $\mathrm{N} 1$ and N2 & 26 & 33 & \\
\hline \multicolumn{4}{|c|}{ Tumor differentiation } \\
\hline I-II & 49 & 60 & 0.147 \\
\hline III & 21 & 16 & \\
\hline \multicolumn{4}{|l|}{ TNM stage } \\
\hline I & 49 & 43 & 0.066 \\
\hline II-III & 21 & 33 & \\
\hline
\end{tabular}

AEP, asparaginyl endopeptidase; TNM, Tumor-Node-Metastasis .

significantly decreased AEP protein levels in EC109 cells with stably transfected recombinant shRNA (Fig. 2C and D), thus shRNAs were considered appropriate for AEP knockdown.

The wound healing assay data revealed that the stable transfection of shRNA1 and shRNA2 into esophageal cancer cells resulted in a significant inhibition of cell migration capacity (Fig. 3A), compared with NC shRNA. In addition, silencing of AEP significantly decreased the invasion capacity into Matrigel as demonstrated by the Transwell assay (Fig. 3B). The tumor cell migration and invasion assay indicated that AEP depletion reduced the invasion, and migration capability of EC109 cell line.

AEP knockdown inhibits EC cell migration and metastasis through targeting MMPs. To determine how AEP influenced the invasive ability of esophageal cancer cells, the expression of several invasion-associated proteins following AEP 
Table II. Univariate and multivariate analyses of factors associated with overall survival and time to relapse.

\begin{tabular}{|c|c|c|c|c|c|c|c|c|}
\hline \multirow[b]{3}{*}{ Variables } & \multicolumn{4}{|c|}{ OS } & \multicolumn{4}{|c|}{ TTR } \\
\hline & \multirow{2}{*}{$\begin{array}{l}\text { Univariate } \\
\text { P-value }\end{array}$} & \multicolumn{3}{|c|}{ Multivariate } & \multirow{2}{*}{$\begin{array}{l}\text { Univariate } \\
\mathrm{P} \text {-value }\end{array}$} & \multicolumn{3}{|c|}{ Multivariate } \\
\hline & & HR & $95 \% \mathrm{CI}$ & P-value & & HR & $95 \% \mathrm{CI}$ & P-value \\
\hline Age, years (>60 vs. $\leq 60$ ) & 0.204 & & & NA & 0.199 & & & NA \\
\hline Sex (male vs. female) & 0.197 & & & NA & 0.050 & & & NA \\
\hline $\begin{array}{l}\text { Drinking history } \\
\text { (yes vs. no) }\end{array}$ & 0.033 & 1.591 & $0.945-2.680$ & 0.080 & 0.263 & & & NA \\
\hline $\begin{array}{l}\text { Smoking history } \\
\text { (yes vs. no) }\end{array}$ & 0.545 & & & NA & 0.135 & & & NA \\
\hline $\begin{array}{l}\text { Family cancer history } \\
\text { (yes vs. no) }\end{array}$ & 0.587 & & & NA & 0.444 & & & NA \\
\hline $\begin{array}{l}\text { T stage } \\
\text { (III and IV vs. I and II) }\end{array}$ & 0.059 & & & NA & 0.238 & & & NA \\
\hline $\mathrm{N}$ stage (N1 and $\mathrm{N} 2$ vs. N0) & 0.000 & 2.000 & $0.828-4.830$ & 0.123 & 0.003 & 1.997 & $0.554-7.202$ & 0.290 \\
\hline Differentiation (III vs. I-II) & 0.661 & & & NA & 0.831 & & & NA \\
\hline TNM stage (III-II vs. I) & 0.000 & 1.683 & $0.694-4.080$ & 0.249 & 0.002 & 2.081 & $0.584-7.409$ & 0.258 \\
\hline AEP tumor (high vs. low) & 0.019 & 1.669 & $0.982-2.838$ & 0.058 & 0.115 & & & NA \\
\hline
\end{tabular}

Univariate analysis was calculated by the Kaplan-Meier method (log-rank test). Multivariate analysis was done using the Cox multivariate proportional hazard regression model with stepwise manner. OS, overall survival; TTR, time to relapse; TNM, tumor-nodes-metastases; HR, hazard ratio; CI, confidential interval; NA, not applicable.
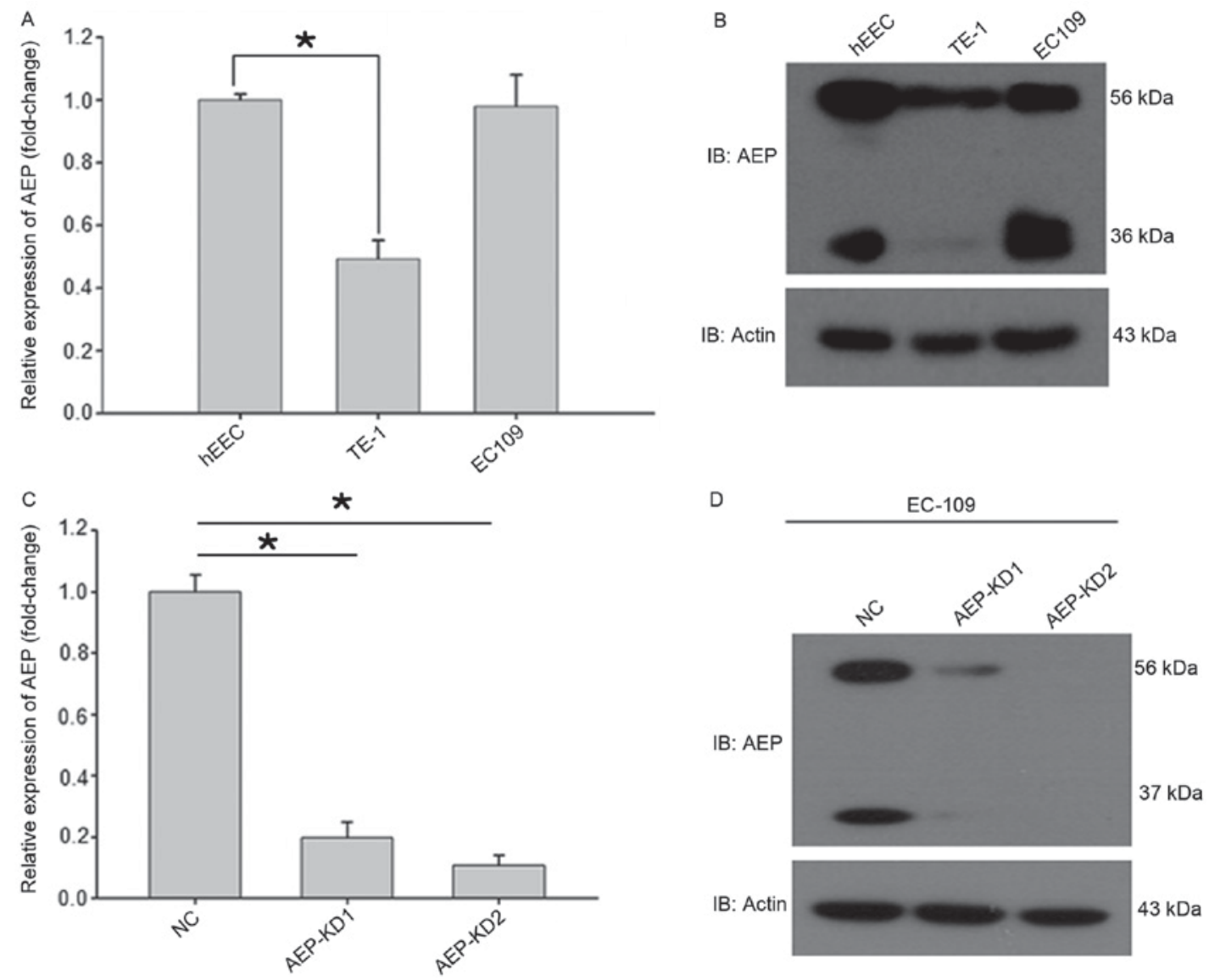

Figure 2. Expression of AEP in esophageal carcinoma cells. (A) RT-qPCR analysis of AEP mRNA levels in EC cells. (B) Western blot analysis of AEP protein levels in EC cells. (C) RT-qPCR analysis of AEP expression in AEP-knocked down EC109 cells. (D) Western blot analysis of AEP expression in AEP-knocked down EC109 cells. AEP, asparaginyl endopeptidase; RT-qPCR, reverse transcription-quantitative polymerase chain reaction; EC, esophageal carcinoma. ${ }^{*} \mathrm{P}<0.001$. 

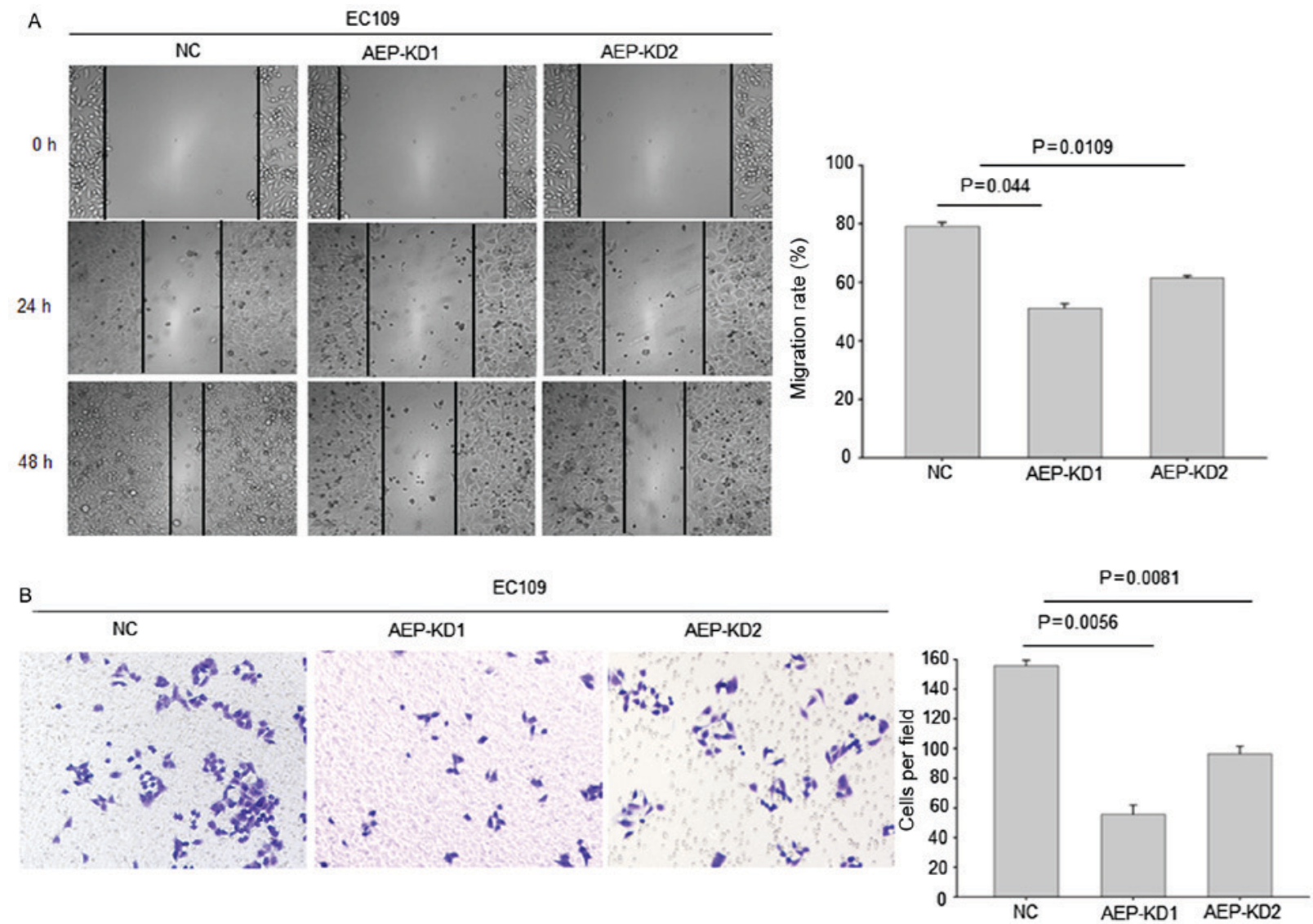

Figure 3. Knockdown of AEP in esophageal carcinoma cells inhibited cell migration and invasion ability. (A) Scratch analysis of EC109 cells with or without AEP knockdown. Images of representative staining are presented. (B) Matrigel-Transwell analysis of EC109 cells with or without AEP knockdown. Images of representative staining are presented. Lines on the graph indicate significance; $\mathrm{P}<0.05$ vs. control. AEP, asparaginyl endopeptidase.

knockdown, compared with control cells was investigated by western blot analysis. Notably, western blot analysis revealed that depletion of AEP markedly reduced MMP2 and MMP3, but not MMP9 expression in AEP-KD-EC109 cells (Fig. 4), compared with control cells. MMPs are known to facilitate cell invasion and metastasis by enzymatically degrading extracellular matrix components (23). Taken together, it was confirmed that AEP promotes metastasis through regulation of MMPs in esophageal tumor cells.

\section{Discussion}

Despite recent advances in esophageal cancer treatment, there has been no significant improvement in the overall survival rate for patients with advanced esophageal cancer. Novel strategies are necessary for early detection and to improve treatment options in esophageal cancer.

Previous reports have indicated that AEP expression positively correlates with clinicopathologic and biological variables in colorectal cancer, and may be a novel oncogene (19-22). Concordantly, it was demonstrated in the present study that AEP was significantly overexpressed in esophageal cancer and was associated with poor prognosis. These observations suggest that AEP may be a potential novel diagnostic biomarker and that AEP inhibitors or monoclonal antibodies may be proposed as esophageal cancer therapies.

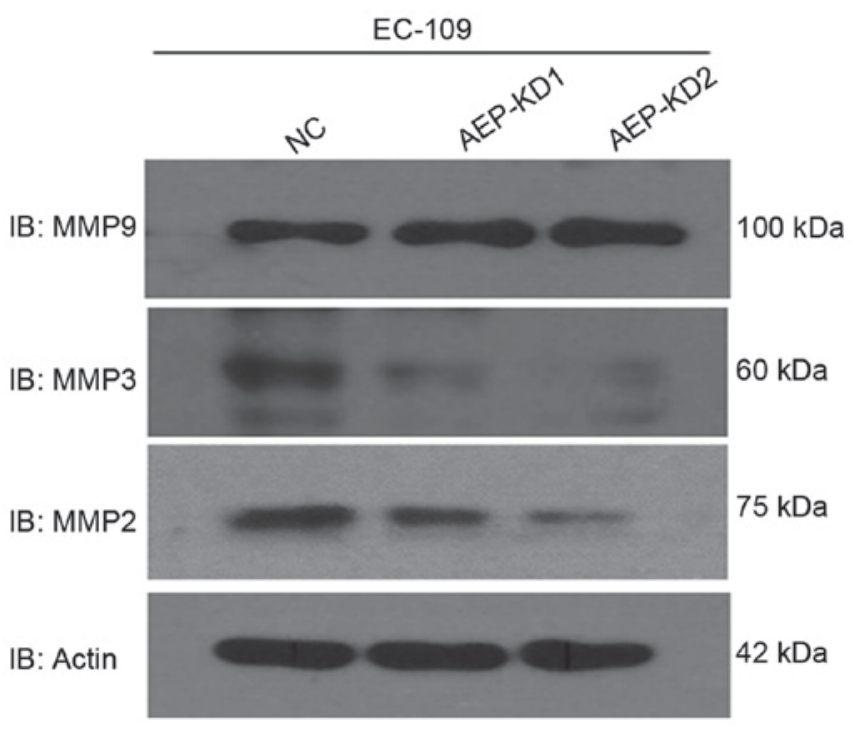

Figure 4. Inhibition of AEP in esophageal carcinoma cells reduced MMP2 and MMP3 protein levels. Western blot analysis of MMPs, including MMP2, MMP3 and MMP9 in EC109 cells with or without AEP knockdown. AEP, asparaginyl endopeptidase; MMP2, matrix metalloproteinase 2; MMP3, matrix metalloproteinase 3; MMP9, matrix metalloproteinase 9.

Previous studies have revealed that AEP is localized in the front of invading cells, and forms a complex with integrins on the surface of lamellipodia and invadopodia (17). The 
binding of AEP to integrins significantly promotes its ability to activate pro-MMP2 and cathepsin L (25). These downstream substrates of AEP have well-established functions in metastasis, which may partially explain the mechanism of AEP metastasis regulation (26). Nevertheless, it is crucial to identify unknown substrates of AEP to further clarify its function in tumor development. The data from the present study demonstrated that secreted AEP is critical for esophageal cancer progression through regulation of MMPs. Degradation of the extracellular matrix by cancer cells are important processes for direct invasion. There are three types of enzymes that effectively degrade extracellular matrix (ECM): MMPs, serine proteinases, and cysteine proteinases. MMPs are known to serve important functions in ECM remodeling during the process of tumor invasion and metastasis. The expression of MMPs was reported to be associated with tumor invasion and lymph node metastasis in EC (27). However, the role of AEP in esophageal cancer progression should be further examined by animal in vivo models.

In summary, data from the present study provides evidence for AEP as a novel biomarker in esophagyeal cancer. In addition, AEP may be of prognostic value and a therapeutic target for the treatment of this disease. Targeting AEP with Aza-Asn-epoxides and its derivatives, which are specific to AEP may have potential therapeutic value.

\section{References}

1. Ferlay J, Soerjomataram I, Dikshit R, Eser S, Mathers C, Rebelo M, Parkin DM, Forman D and Bray F: Cancer incidence and mortality worldwide: Sources, methods and major patterns in GLOBOCAN 2012. Int J Cancer 136: E359--E386, 2015.

2. Vermeulen E, Zamora-Ros R, Duell EJ, Luján-Barroso L, Boeing H, Aleksandrova K, Bueno-de-Mesquita HB, Scalbert A, Romieu I, Fedirko V, et al: Dietary flavonoid intake and esophageal cancer risk in the European prospective investigation into cancer and nutrition cohort. Am J Epidemiol 178: 570-581, 2013

3. Enzinger PC and Mayer RJ: Esophageal cancer. N Engl J Med 349: 2241-2252, 2003.

4. Pennathur A, Farkas A, Krasinskas AM, Ferson PF, Gooding WE, Gibson MK, Schuchert MJ, Landreneau RJ and Luketich JD: Esophagectomy for T1 esophageal cancer: Outcomes in 100 patients and implications for endoscopic therapy. Ann Thorac Surg 87: 1048-1055, 2009.

5. Hayashi Y, Correa AM, Hofstetter WL, Vaporciyan AA, Mehran RJ, Rice DC, Suzuki A, Lee JH, Bhutani MS, Welsh J, et al: Patients with high body mass index tend to have lower stage of esophageal carcinoma at diagnosis. Dis Esophagus 25: 614-622, 2012.

6. Zheng J, Xu C, Chu D, Zhang X, Li J, Ji G, Hong L, Feng Q, Li X, Wu G, et al: Human leukocyte antigen $\mathrm{G}$ is associated with esophageal squamous cell carcinoma progression and poor prognosis. Immunol Lett 161: 13-19, 2014.

7. Harris KS, Durek T, Kaas Q, Poth AG, Gilding EK, Conlan BF, Saska I, Daly NL, van der Weerden NL, Craik DJ and Anderson MA: Efficient backbone cyclization of linear peptides by a recombinant asparaginyl endopeptidase. Nat Commun 6: 10199, 2015.

8. Zhao L, Hua T, Crowley C, Ru H, Ni X, Shaw N, Jiao L, Ding W, $\mathrm{Qu} \mathrm{L}$, Hung LW, et al: Structural analysis of asparaginyl endopeptidase reveals the activation mechanism and a reversible intermediate maturation stage. Cell Res 24: 344-358, 2014.

9. Miller G, Matthews SP, Reinheckel T, Fleming S and Watts C: Asparagine endopeptidase is required for normal kidney physiology and homeostasis. FASEB J 25: 1606-1617, 2011.

10. Descamps D, Le Gars M, Balloy V, Barbier D, Maschalidi S, Tohme M, Chignard M, Ramphal R, Manoury B and Sallenave JM: Toll-like receptor 5 (TLR5), IL-1 $\beta$ secretion, and asparagine endopeptidase are critical factors for alveolar macrophage phagocytosis and bacterial killing. Proc Natl Acad Sci USA 109: 1619-1624, 2012.
11. Sepulveda FE, Maschalidi S, Colisson R, Heslop L, Ghirelli C, Sakka E, Lennon-Duménil AM, Amigorena S, Cabanie L and Manoury B: Critical role for asparagine endopeptidase in endocytic Toll-like receptor signaling in dendritic cells. Immunity 31 : 737-748, 2009.

12. Morita Y, Araki H, Sugimoto T, Takeuchi K, Yamane T, Maeda T, Yamamoto Y, Nishi K, Asano M, Shirahama-Noda K, et al: Legumain/asparaginyl endopeptidase controls extracellular matrix remodeling through the degradation of fibronectin in mouse renal proximal tubular cells. FEBS Lett 581: 1417-1424, 2007.

13. Choi SJ, Reddy SV, Devlin RD, Menaa C, Chung H, Boyce BF and Roodman GD: Identification of human asparaginyl endopeptidase (legumain) as an inhibitor of osteoclast formation and bone resorption. J Biol Chem 274: 27747-27753, 1999.

14. Xing W, Baylink D, Kesavan C, Hu Y, Kapoor S, Chadwick RB and Mohan S: Global gene expression analysis in the bones reveals involvement of several novel genes and pathways in mediating an anabolic response of mechanical loading in mice. J Cell Biochem 96: 1049-1060, 2005.

15. Dickinson D: Cysteine peptidases of mammals: Their biological roles and potential effects in the oral cavity and other tissues in health and disease. Crit Rev Oral Biol Med 13: 238-275, 2002.

16. Gawenda J, Traub F, Lück HJ, Kreipe H and von Wasielewski R: Legumain expression as a prognostic factor in breast cancer patients. Breast Cancer Res Treat 102: 1-6, 2007.

17. Brix K, McInnes J, Al-Hashimi A, Rehders M, Tamhane T and Haugen MH: Proteolysis mediated by cysteine cathepsins and legumain-recent advances and cell biological challenges. Protoplasma 252: 755-774, 2015.

18. Holland M, Castro FV, Alexander S, Smith D, Liu J, Walker M, Bitton D, Mulryan K, Ashton G, Blaylock M, et al: RAC2, AEP, and ICAM1 expression are associated with CNS disease in a mouse model of pre-B childhood acute lymphoblastic leukemia. Blood 118: 638-649, 2011.

19. Chen JM, Dando PM, Rawlings ND, Brown MA, Young NE, Stevens RA, Hewitt E, Watts C and Barrett AJ: Cloning, isolation, and characterization of mammalian legumain, an asparaginyl endopeptidase. J Biol Chem 272: 8090-8098, 1997.

20. Liu C, Sun C, Huang H, Janda K and Edgington T: Overexpression of legumain in tumors is significant for invasion/metastasis and a candidate enzymatic target for prodrug therapy. Cancer Res 63 : 2957-2964, 2003

21. Murthy RV, Arbman G, Gao J, Roodman GD and Sun XF: Legumain expression in relation to clinicopathologic and biological variables in colorectal cancer. Clin Cancer Res 11: 2293-2299, 2005.

22. Ohno Y, Nakashima J, Izumi M, Ohori M, Hashimoto T and Tachibana M: Association of legumain expression pattern with prostate cancer invasiveness and aggressiveness. World J Urol 31: 359-364, 2013.

23. Liu JK, Forman S, Moorthy CR and Benzil DL: Update on treatment modalities for optic nerve sheath meningiomas. Neurosurg Focus 14: e7, 2003.

24. Napier KJ, Scheerer M and Misra S: Esophageal cancer: A Review of epidemiology, pathogenesis, staging workup and treatment modalities. World J Gastrointest Oncol 6: 112-120, 2014.

25. Liu X, Wang Z, Zhang G, Zhu Q, Zeng H, Wang T, Gao F, Qi Z, Zhang J and Wang R: High TRAF6 expression is associated with esophageal carcinoma recurrence and prompts cancer cell invasion. Oncol Res 25: 485-493, 2017.

26. Lin Y, Qiu Y, Xu C, Liu Q, Peng B, Kaufmann GF, Chen X, Lan B, Wei C, Lu D, et al: Functional role of asparaginyl endopeptidase ubiquitination by TRAF6 in tumor invasion and metastasis. J Natl Cancer Inst 106: dju012, 2014.

27. Murray GI, Duncan ME, O'Neil P, McKay JA, Melvin WT and Fothergill JE: Matrix metalloproteinase-1 is associated with poor prognosis in oesophageal cancer. J Pathol 185: 256-261, 1998. 